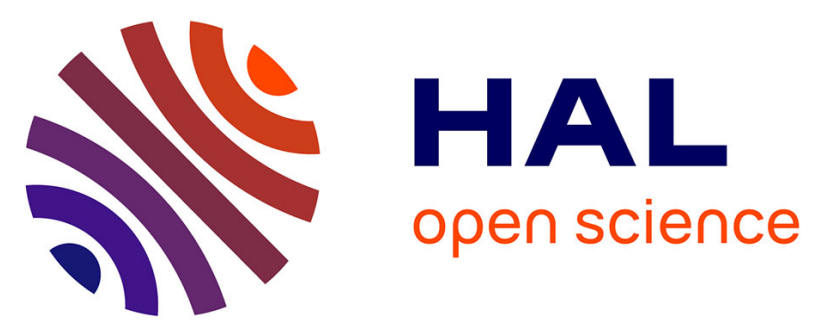

\title{
How generalizable to community samples are clinical trial results for treatment of nicotine dependence: A comparison of common eligibility criteria with respondents of a large representative general population survey
}

Yann Le Strat, Jürgen Rehm, Bernard Le Foll

\section{To cite this version:}

Yann Le Strat, Jürgen Rehm, Bernard Le Foll. How generalizable to community samples are clinical trial results for treatment of nicotine dependence: A comparison of common eligibility criteria with respondents of a large representative general population survey. Tobacco Control, 2011, 20 (5), pp.338. 10.1136/tc.2010.038703 . hal-00615112

\author{
HAL Id: hal-00615112 \\ https://hal.science/hal-00615112
}

Submitted on 18 Aug 2011

HAL is a multi-disciplinary open access archive for the deposit and dissemination of scientific research documents, whether they are published or not. The documents may come from teaching and research institutions in France or abroad, or from public or private research centers.
L'archive ouverte pluridisciplinaire HAL, est destinée au dépôt et à la diffusion de documents scientifiques de niveau recherche, publiés ou non, émanant des établissements d'enseignement et de recherche français ou étrangers, des laboratoires publics ou privés. 
1 How generalizable to community samples are clinical trial results for treatment of nicotine dependence:

5

6

7

8 large representative general population survey

\section{A comparison of common eligibility criteria with respondents of a} (1)

9

${ }^{1}$ Translational Addiction Research Laboratory, Centre for Addiction and Mental Health, Toronto, Ontario, Canada.

${ }^{2}$ Addiction Program, Centre for Addiction and Mental Health, Toronto, Ontario, Canada

${ }^{3}$ INSERM U894, Team 1, Centre for Psychiatry and Neurosciences, 2 ter rue d'Alesia, 75014, Paris, France.

${ }^{4}$ Department of Psychiatry, Louis-Mourier Hospital, AP-HP, Colombes, France.

${ }^{5}$ Faculty of Medicine, University Paris 7 Denis-Diderot, Paris, France.

${ }^{6}$ Centre for Addiction and Mental Health (CAMH), Toronto, Canada

${ }^{7}$ Dalla Lana School of Public Health (DLSPH), University of Toronto, Canada

${ }^{8}$ Institute for Clinical Psychology and Psychotherapy, TU Dresden, Germany 


\section{Abstract}

2

3 Objectives: To examine the generalizability of findings from clinical trials of individuals with

4 nicotine dependence to a large general population sample.

5 Methods: Eligibility criteria were drawn from typical criteria of clinical trials for nicotine

6 dependence. The National Epidemiological Survey on Alcohol and Related Conditions

7 (NESARC), a large national sample of the United States population, was used to assess how

8 many potentially eligible people would fulfil the eligibility criteria. NESARC interviewed

9 more than 43,000 adults aged 18 years and older. We applied a standard set of eligibility

10 criteria representative of smoking cessation clinical trials to all the 4,962 adults with past 12

11 months nicotine dependence, and then to a sub-group of participants motivated to quit

$12(\mathrm{n}=4,121)$.

13 Results: We found that approximately 6 out of ten participants (65.89\%) with nicotine

14 dependence were excluded by at least one criterion. In the sub-group of nicotine dependent

15 participant motivated to quit, more than half (58.60\%) were excluded by at least one criterion.

16 For the overall sample, smoking 10 cigarettes per day or less and lack of motivation to quit

17 were the two criteria leading to exclusion for the greatest percentage of individuals $(32.02 \%$

18 and $17.60 \%$ respectively). For the sample motivated to quit, smoking less than 10 cigarettes

19 per day or less and current depression led most frequently to exclusion $(33.79 \%$ and $15.71 \%$

20 respectively).

21 Conclusions: Further studies and interventions should explore efficacy of tobacco treatment

22 interventions in larger segment of the population, notably on the subpopulations of people

23 with nicotine dependence who smoke less than 10 cigarettes per day or with comorbid 24 depression. 


\section{What this paper adds}

2 Clinical trials for treatment of nicotine dependence often exclude sizable parts of the general

3 population with nicotine dependence. This article quantifies the lack of generalizability by

4 using a large representative US general population survey. It was found, that the majority of

5 nicotine dependent subjects would have been excluded from participating in clinical trials.

6 
1 Clinical guidelines are developed based on the evidence obtained using clinical trials [1-4]. In

2 smoking cessation trials, exclusion and eligibility criteria are highly used in order to maximize

3 treatment efficacy and safety [5]. However, they may impair the external validity of the study,

4 since they often exclude a substantial proportion of participants, resulting in a selection bias

5 [5], and extending the gap between research and clinical practice [6]. Common exclusion

6 criteria include age, current or past psychiatric/drug disorder, minimal levels of tobacco use

7 and medical conditions [7]. There is a risk that this selection of the participants involved

8 affects the results of the treatment trial for nicotine dependence as it is the case in other

9 domains $[8,9]$. The impact of eligibility/exclusion criteria on the generalizability of clinical

10 trials has been described for antidepressant efficacy trials [5, 10-14], antipsychotic efficacy

11 trials [15-17] and clinical trials for alcohol dependence [18-21] and cannabis dependence [22].

12 The percentage of subjects excluded by these criteria ranged between $50.5 \%$ and $75.8 \%$ in

13 these studies $[10,18]$.

14 The impact of eligibility criteria in smoking cessation trials has been discussed in the

15 literature [7, 23-29]. As called by CONSORT guidelines, several studies reported the reasons

16 for ineligibility [7, 28]. For example, Robinson et al. screened 1,347 adolescents for a nicotine

17 replacement treatment trial, and found that only $24.4 \%$ were eligible for inclusion in the trial

18 [28]. The main reason for ineligibility was a failure to meet minimum requirement regarding

19 the number of cigarettes smoked per day and/or a low level of nicotine dependence (criterion

20 present in 39.1\% of ineligible individuals) [28]. More recently, Kamholtz et al. assessed 97

21 non-eligible and 201 eligible participants in a laboratory research on smoking [7]. They

22 reported that the main reasons for ineligibility were current alcohol and substance use

23 disorders (present in $23.7 \%$ and $11.3 \%$ of ineligible individuals respectively) and failure to

24 meet minimum requirement regarding cigarettes smoked per day (24.7\%). However, when 
1 comparing eligible and non-eligible participants, they found no difference in levels of nicotine

2 dependence as assessed by the Fagerström Test for Nicotine Dependence Questionnaire [30].

3

4 A limitation of the clinical trials reported in the literature is that they rely on a sample of 5 participants, and therefore cannot be extrapolated to individuals with nicotine dependence in

6 the community. As suggested by Robinson et al.[28], and in order to understand the impact of 7 eligibility criteria in the population, an analysis of the application of eligibility criteria to a 8 representative general population sample of individuals with nicotine dependence is required.

9 In that view, we assessed the effect of exclusion criteria commonly applied in clinical trials in 10 a large, nationally representative sample, the National Epidemiological Survey on Alcohol 11 and Related Conditions (NESARC). The NESARC is a survey conducted in the United States, 12 including a broad range of psychiatric disorders as well as measures of various medical 13 conditions. We used a method previously described by Blanco et al. in clinical trials for major 14 depression [10] and alcohol dependence [18]. We wanted to estimate the population 15 generalizability of clinical trials for nicotine dependent individuals. We applied common clinical trial eligibility criteria to all individuals with a current diagnosis of nicotine 17 dependence, and then to a subsample of individuals who were motivated to quit, to examine proportion who would have been excluded in treatment trials for nicotine dependence.

\section{Methods}

21 Participants

22 Subjects were participants in NESARC, a nationally representative face-to-face survey of 2343,093 respondents aged 18 years and older (response rate, 81\%), conducted by the National 24 Institute on Alcohol Abuse and Alcoholism (NIAAA) in 2001-2002 [31, 32]. The NESARC 25 assessed the civilian non-institutionalized population residing in the United States. African- 
1 Americans and Hispanics were oversampled, as were young adults. The research protocol,

2 including informed consent procedures, received full ethical review and approval from the US

3 Census Bureau and the Office of Management and Budget. Data were adjusted for

4 oversampling and household- and person-level nonresponse. The weighted data were then

5 further adjusted to represent the civilian population in the United States based on the 2000

6 Census.

7

8 Measure of Nicotine Dependence

9 The NESARC used the National Institute on Alcohol Abuse and Alcoholism's Alcohol Use

10 Disorder and Associated Disabilities Interview Schedule DSM-IV version (AUDADIS-IV), a

11 structured diagnostic interview made for non-clinician interviewers [33]. Algorithms were

12 designed to produce diagnoses of nicotine dependence consistent with the final DSM-IV

13 criteria. For example, the "using nicotine to relieve or avoid withdrawal symptoms" criterion

14 was defined by the following 4 items: (1) the use of nicotine as soon as waking up, (2) the use

15 of nicotine after being in a situation in which use was forbidden, (3) the use of nicotine to

16 decrease nicotine withdrawal symptoms, and (4) waking up in the middle of the night to use

17 tobacco [34]. Several studies have documented good to excellent retest reliability [35].

19 Data Analysis

20 Exclusion criteria commonly applied in clinical trials of treatments for nicotine dependence

21 (see below in Clinical Trial Exclusion Criteria) were applied to individuals from the general 22 population to determine the proportion of individuals from the general population with current 23 nicotine dependence according to DSM-IV criteria that would be eligible for the clinical trials.

24 The same criteria were applied to the subset of individuals with current nicotine dependence 25 motivated to quit, examining potential differences in eligibility between motivated and less 
1 motivated individuals, using a pattern of analysis described elsewhere $[10,18]$. In these

2 studies, Blanco et al. used attempts to quit a substance in the last 12 months as a proxy

3 variable for motivation to quit in the future $[10,18]$.

4 The appropriate statistical weight was employed when mentioned to ensure the data were 5 representative of the population.

6

7

8

9

10

11

12

21 time during the past year?").

22 The presence of a recent cardiac event (criterion 2) was assessed by series of questions on 23 chest pain, angina pectoris, heart attack, myocardial infarction or any other form of heart 24 disease in the last 12 months, and whether the diagnosis was confirmed by a physician.

\section{Clinical Trial Exclusion Criteria}

We examined eligibility criteria from clinical trials included in a recent meta-analysis comparing the effectiveness of pharmacotherapies for smoking cessation [36]. We collected all eligibility criteria from 54 randomized clinical trials [37-92], and ranked them according to their frequency. Criteria included in more than $10 \%$ of the studies are listed in Table 1 . The median of the number of eligibility criteria used in a study was 12 (considering not only criteria included in Table 1 but also criteria present in less than $10 \%$ of the studies). We thus applied the 12 most frequently used criteria to the NESARC sample.

The percentages of individuals excluded by criteria $1,3,5,6,7,8,11$ and 12 were estimated from data collected by the AUDADIS-IV. Information to approximate criterion 4 (use of psychotropic medications), criterion 9 (use of bupropion or nicotine replacement therapy) and criterion 10 (history of eating disorder) was not available in the NESARC.

Criterion 1 (pregnancy status) was assessed with a single question ("Were you pregnant at any Criterion 3 ("Smoking 10 cigarettes per day or less on average ") was applied using a 12month time frame (as it is assessed in the NESARC). 
1 Criterion 5 (“Alcohol dependence ") was defined having a diagnosis of alcohol dependence

2 within the last 12 months.

3 Criterion 6 ("Being not motivated to quit smoking ") was assessed by 2 questions: "In you

4 entire life, did you ever, more than once, want to stop or cut down your tobacco use?'), and

5 "Did this happen in the last 12 months?". Participants who respond positively to both

6 questions were classified as being motivated to quit smoking. Other participants were

7 classified as being not motivated to quit smoking. This assessment is therefore at variance

8 with standard questions about motivation in research trials, who usually asked whether

9 participants want to cut down/attempt to stop in the future rather than if they have done so in

10 the past.

11 Criterion 7 ("Dependence to other drugs") was defined having a diagnosis of dependence to 12 an illicit substance (either sedatives, tranquilizers, opiates, stimulants, hallucinogens, 13 cannabis, cocaine (including crack cocaine), inhalants/solvents, heroin, or other drugs) within 14 the last 12 months.

15 Criterion 8 ("Having a current depression") was assessed using the criteria for Major 16 Depressive Disorder within the last 12 months.

17 Criterion 11 ("Having a current psychosis") was assessed by 2 questions: "Did a doctor or 18 other health professional ever diagnose you with schizophrenia or psychotic illness or 19 episode?". Participants who respond positively to this were classified as having "psychosis".

20 Participants with a lifetime history of mania were classified as having a bipolar disorder 21 (Criterion 12). We choose to consider only bipolar type I disorder because hypomania, the 22 hallmark of bipolar type II disorder, is a more subtle form of the disorder and therefore not 23 likely to be screened in routine in eligibility assessments of clinical trials for nicotine 24 dependent individuals. For the same reason, we considered participants as having bipolar 25 disorder if they had a history of mania even if manic episodes were induced by a substance or 
1 an illness, and did not restricted our analysis to independent bipolar disorders. As a control,

2 we did a sensitivity analysis to examine how the results would change if (i) substance and

3 illness induced mania were ruled out, and (ii) if bipolar type II disorder was also included in

4 the eligibility criteria (with substance and illness induced disorders being ruled out).

5

6 Analysis Plan

7 We first determined the number and percentage of nicotine dependent participants of the

8 NESARC who would be excluded by individually applying each of the 12 most frequent

9 eligibility criteria reported previously. . Because individuals might have been excluded by

more than 1 criterion, we also calculated the overall percentage of subjects who would have

11 been excluded by the simultaneous application of all the measurable criteria. We conducted

12 these analyses for all individuals with a current DSM-IV diagnosis of nicotine dependence

$13(\mathrm{n}=4,962)$, and for the sub-sample of individuals who want to stop or cut down on tobacco use

14 in the last 12 months $(n=4,121)$. Weighted prevalence estimates and $95 \%$ confidence intervals

15 were computed using SUDAAN, version 10.01 (Research Triangle Park, NC). This software

16 implements a Taylor linearization to adjust for complex survey sampling design effects

17 including clustering data.

\section{Results}

21 The percentage of subjects excluded by at least one criterion was $65.89 \%$ among respondents

22 who met DSM-IV criteria for nicotine dependence and $58.60 \%$ of those motivated to quit

23 smoking in the past year (Table 2)

24 The percentage of respondents excluded due to the application of a single criterion ranged

25 from $2.14 \%$ (lifetime diagnosis of psychosis) to $32.02 \%$ (smoking less than 10 cigarettes per 
1 day) in the overall sample of respondents with nicotine dependence, and $1.95 \%$ (lifetime

2 diagnosis of psychosis) to $33.79 \%$ (smoking less than 10 cigarettes per day) among those

3 motivated to quit smoking.

4

5 For the overall sample, smoking 10 cigarettes per day or less and lacking motivation to quit

6 were the two criteria including the highest percentage of individuals. For the treatment-

7 seeking sample, having a current depression and smoking 10 cigarettes per day or less were

8 the criteria comprising the greatest percentage of individuals who would not be eligible.

9 Current alcohol dependence and a history of bipolar disorder also excluded a notable 10 proportion of individuals in both samples (Table 2).

11 A history of bipolar disorder (type I) was present in $10.33 \%$ of the participants with nicotine 12 dependence (CI 95\%: 8.16-10.50). As a control, ruling out illness- and substance-induced 13 mania only slightly decreased to $9.26 \%$ the percentage of participants excluded because of 14 this criteria (CI 95\%:8.16-10.50). When bipolar type II disorder was also included in this 15 eligibility criteria (substance- and illness-induced disorder still ruled out), the percentage of 16 participants excluded because of this criteria raised to $14.70 \%$ (95\%CI: $13.55-15.93)$. The 17 overall exclusion rate was $65.58 \%$ when considering bipolar I disorder after ruling out illness 18 and substance induced mania, and $66.8 \%$ when considering bipolar I and II after ruling out 19 illness and substance induced mania, compared to an overall exclusion rate of $64.13 \%$ when 20 considering only bipolar I disorder even if manic episodes were induced by a substance or an 21 illness. This suggests that the criteria used to define bipolar disorder have little or no impact 22 on the overall inclusion rate.

23 More than 6 out of ten respondents from the full nicotine dependent sample and more than 24 half of the subsample of individuals motivated to quit smoking would have been excluded by 25 one or more of the study criteria. 


\section{Discussion}

4 This study ascertains the proportion of community-dwelling adults with nicotine dependence

5 that would have been eligible for a typical nicotine dependence treatment study. The results of

6 this study suggest that traditional criteria used in nicotine dependence trials tend to exclude

7 from participation half of individuals with nicotine dependence who are likely to seek out a

8 treatment. These results are in line with previous findings, suggesting that a majority of

9 individuals who were screened for a nicotine cessation trail were not eligible to participate to

10 the trial. For example, among the 54 randomized clinical trials assessed in the present paper

11 [37-92], the ineligibility rates varied widely, ranging from 12.9\% [37]to 85.31[56]..

12 Consistent with the existing literature, we found that a lack of motivation to quit and a low

13 level of cigarette consumption explain a large proportion of ineligibility [7, 28].

15 Our study has several limitations.

16 First of all, our exclusion criteria are somehow arbitrary. ,We considered eligibility criteria

17 from 54 randomized clinical trials included in a recent meta-analysis [36], but the use of

18 another methodology could have led to other results. An important point is that the exclusion

19 criterion based on alcohol consumption varies widely across studies. It has been emphasized

20 that an alcohol-related exclusion criterion appears frequently in smoking cessation

21 pharmacotherapy trials $[29,93]$. A recent review showed that $41.6 \%$ of trials (45 of 125

22 nicotine replacement trails, 15 of 22 bupropion trials and 3 of 3 varenicline trials) involved

23 exclusion of participants with either current or recent alcohol problems, leading to a lack of

24 information on the effects of alcohol use disorders on smoking cessation [29, 93].

25 A second restriction is that 3 of the 12 exclusion criteria initially included could not be 26 operationalized in our study, because the relevant information was not assessed in the 
1 NESARC sample, including (1) participants currently taking a psychotropic medication, (2)

2 participants "currently taking Bupropion or nicotine replacement therapy", and (3) having an

3 eating disorder,. This may theoretically lead to an underestimation of the proportion of

4 patients excluded in clinical trials. However, these criteria are rarely met in the general

5 population. For example, the estimated percentage of smokers in Australia who used

6 bupropion in a year was only $3.6 \%$ in 2005 [94]. Eating disorders have a low prevalence,

7 affecting less than $4.5 \%$ [95] of the general population. While an investigation of the impact

8 of these exclusion criteria on the generalizability of clinical trials is required in a future study,

9 they are not likely to exclude a significant proportion of smokers.

10 A third limitation is that the NESARC sample included only individuals aged 18 years or

11 older. Information was unavailable for adolescents, who may be have a lower level of

12 comorbidities, and may therefore be more likely to be eligible for clinical trials.

13 Some of the criteria have been implemented for safety reasons (e.g pregnancy, potential

14 interaction with psychotropic drugs or with alcohol) while some other may contribute to

15 stigmatize a significant proportion of the population (e.g having a history of substance abuse

16 with no use within the last 12 months should not be considered as valid exclusion criteria in a

17 clinical trial).

18 The exclusion of participant with alcohol dependence is particularly damageable, since

19 nicotine dependence is a major issue in alcohol-dependent patients. For example, smokers

20 with a lifetime history of alcohol dependence are more likely to die of smoking-related

21 diseases rather than from alcohol-related diseases [96]. Moreover, alcohol-dependent subjects

22 suffering from nicotine dependence have a higher prevalence of nearly all psychiatric and

23 addictive disorders [97], making treatment for smoking cessation in this specific population a

24 unmet need. 
1 In summary, we found that the current criteria of eligibility applied in clinical trial involving

2 nicotine dependent individuals are highly restrictive, and exclude a majority of participants,

3 thus limiting the generalizability of their findings. Particularly, our findings suggested that (1)

4 individuals smoking few cigarettes in a day or (2) having a current or past history of mood

5 disorders (major depressive disorder or bipolar disorder) are underrepresented in clinical

6 trials. These two related groups should be the focus of further investigations.

7 


\section{Declaration of interest}

2

3 None.

4 The Corresponding Author has the right to grant on behalf of all authors and does grant on

5 behalf of all authors, an exclusive licence (or non-exclusive for government employees) on a

6 worldwide basis to the BMJ Publishing Group Ltd and its Licensees to permit this article (if

7 accepted) to be published in Tobacco Control and any other BMJPGL products to

8 exploit all subsidiary rights, as set out in our licence.

9

10 Acknowledgments

11

12 The National Epidemiologic Survey on Alcohol and Related Conditions was sponsored by the

13 National Institute on Alcohol Abuse and Alcoholism and funded, in part, by the Intramural

14 Program of DHHS-NIH-NIAAA.

15 YLS is funded by a grant from the Société Française de Tabacologie and the Addiction 16 Program of CAMH.

17

18 
1 Table 1. Eligibility criteria in 54 randomized clinical trials assessing pharmacotherapies

2 for smoking cessation

3

4

\begin{tabular}{|c|c|c|}
\hline $\begin{array}{l}\text { Eligibility criteria present in more } \\
\text { than } 10 \% \text { of the studies (ranked by } \\
\text { frequency) }\end{array}$ & Studies using the criteria [reference number] & $\begin{array}{l}\text { Number of } \\
\text { studies using the } \\
\text { criteria } \\
\mathrm{N}=54\end{array}$ \\
\hline 1. Pregnancy & $\begin{array}{l}{[37,38,43-48,50-54,56,58-65,67-69,71-82,} \\
84,98,99]\end{array}$ & 40 \\
\hline 2. Cardiovascular disorder & $\begin{array}{l}{[37,38,41-46,48,49,51-53,58-62,64,65,67-} \\
69,71-76,78-82,84,85,92,98,99]\end{array}$ & 38 \\
\hline $\begin{array}{l}\text { 3. Smoking at least } 10 \text { cigarettes } \\
\text { per day on average }\end{array}$ & $\begin{array}{l}{[37-49,53-56,58-63,66,67,69-74,76,78,79,} \\
83,89,92]\end{array}$ & 37 \\
\hline $\begin{array}{l}\text { 4. Currently/past } 6 \text { months take } \\
\text { any psychotropic medication }\end{array}$ & $\begin{array}{l}{[38,39,42,45,47,49,52-54,56,58-60,62-64,} \\
66-72,74-76,78,79,81,82,89]\end{array}$ & 32 \\
\hline 5. Alcohol dependence & $\begin{array}{l}{[38,40-44,47,48,50,53,54,58-60,62-65,68,} \\
70-72,74-76,78,79,81,82,86]\end{array}$ & 30 \\
\hline 6. Motivated to quit & $\begin{array}{l}{[37-39,43,44,46,48-51,54,55,58,59,61,63,} \\
65,67,69,71-73,76,78,79,81,82,87,98]\end{array}$ & 29 \\
\hline 7. Dependence to other drugs & $\begin{array}{l}{[38,40-44,50,54,58-60,62-66,68,70-72,74-} \\
76,78,79,81,82]\end{array}$ & 27 \\
\hline 8. Having a current depression & $\begin{array}{l}{[37,38,40-43,45-49,52,54,55,59,63,66,70,} \\
73,74,76,77]\end{array}$ & 22 \\
\hline $\begin{array}{l}\text { 9. Currently/past } 6 \text { months take } \\
\text { Bupropion and/or NRT }\end{array}$ & $\begin{array}{l}{[39-43,46,51-55,58,59,61,63,64,66,69,78,} \\
81,87]\end{array}$ & 21 \\
\hline 10. Eating disorder & $\begin{array}{l}{[37-39,41-44,47-49,52,54,55,59,63,66,70,} \\
73,74,76]\end{array}$ & 20 \\
\hline 11. Having a current psychosis & $\begin{array}{l}{[37,38,40-43,47-49,52,59,63,66,70,73,74,} \\
76,77,86]\end{array}$ & 19 \\
\hline 12. Bipolar disorder & $\begin{array}{l}{[37,38,40-43,47-49,52,59,63,66,70,73,74,} \\
76,77]\end{array}$ & 18 \\
\hline 13. Having current Panic disorder & $\begin{array}{l}{[37,38,40-43,47-49,59,63,66,70,73,74,76,} \\
77]\end{array}$ & 17 \\
\hline $\begin{array}{l}\text { 14. Using any form of tobacco } \\
\text { other than cigarettes }\end{array}$ & $\begin{array}{l}{[38,40,42,46,48,53,59-61,64,71,74,75,} \\
79,82,87]\end{array}$ & 16 \\
\hline 15. Age less than 75 yo & {$[38,40-45,60,62,69,74-77,81,99]$} & 16 \\
\hline 16. Renal disease & {$[37-39,41-46,48,49,55,59,92]$} & 14 \\
\hline 17. History/risk of seizure & {$[39,41,43,44,46-49,52,54,55,59,63]$} & 13 \\
\hline
\end{tabular}




\begin{tabular}{|l|l|l|}
\hline 18. High blood pressure & {$[41-45,48,49,51,59,68,69,72,81]$} & 13 \\
\hline 19. Liver disease & {$[37-39,41-46,48,49,55,92]$} & 13 \\
\hline 20. Skin disorder & $\begin{array}{l}{[58,60,62,67,69,71,73,74,76,77,79,80,} \\
82]\end{array}$ & 13 \\
\hline 21. Neurological disease & {$[37-39,41,44,48,49,55,59,92]$} & 10 \\
\hline 22. Peptic ulcer disease & {$[45,51,59,68,71,72,80,84,99]$} & 9 \\
\hline $\begin{array}{l}\text { 23. Diabetes } \\
\text { 24. High alveolar carbon } \\
\text { monoxide level }\end{array}$ & {$[9,13,22-24,35,38,51,53]$} & 9 \\
\hline $\begin{array}{l}\text { 25. Allergies } \\
{[53,55,56,70,74,76]}\end{array}$ & 6 \\
\hline 3 & {$[43,48,52,65,69,70]$} & 6 \\
\hline
\end{tabular}


1 Table 2. Estimated percentage of adults with nicotine dependence in the NESARC

2 excluded from typical clinical trials of treatments for nicotine dependence by traditional

3 efficacy eligibility criteria

4

\begin{tabular}{|c|c|c|}
\hline Exclusion Variable & $\begin{array}{c}\text { Current nicotine } \\
\text { dependence } \\
(\mathrm{N}=4,962) \\
\%(95 \% \mathrm{CI})\end{array}$ & $\begin{array}{l}\text { Motivated to quit } \\
\text { smoking sample } \\
\qquad(\mathrm{N}=4,121) \\
\%(95 \% \mathrm{CI})\end{array}$ \\
\hline \multicolumn{3}{|l|}{ Traditional efficacy exclusion criteria ${ }^{\mathrm{a}}$} \\
\hline 1. Pregnancy & $3.19(2.67-3.80)$ & $3.46(2.89-4.13)$ \\
\hline 2. Cardiovascular disorder & $6.84(5.99-7.80)$ & $6.66(5.77-7.68)$ \\
\hline $\begin{array}{l}\text { 3. Smoking less than } 10 \text { cigarettes per day on } \\
\text { average }\end{array}$ & $32.02(29.98-34.14)$ & $33.79(31.79-35.85)$ \\
\hline $\begin{array}{l}\text { 4. Currently/past } 6 \text { months take any } \\
\text { psychotropic medication }\end{array}$ & NA & NA \\
\hline 5. High alcohol consumption/alcohol abuse & $13.55(12.27-14.82)$ & $12.96(11.73-14.30)$ \\
\hline 6. Not motivated to quit & $17.60(16.18-19.11)_{-}$ & 0.00 \\
\hline 7. Use/abuse of other drugs & $3.40(2.83-4.07)$ & $3.24(2.64-3.98)$ \\
\hline 8. Having a current depression & $16.62(15.41-17.92)$ & $15.71(14.41-17.10)$ \\
\hline $\begin{array}{l}\text { 9. Currently/past } 6 \text { months take Bupropion } \\
\text { and/or NRT }\end{array}$ & NA & NA \\
\hline 10. Eating disorder & NA & NA \\
\hline 11. History of psychosis & $2.14(1.72-2.67)$ & $1.95(1.52-2.51)$ \\
\hline 12. History of bipolar disorder & $10.33(9.13-11.66)$ & $9.81(8.59-11.18)$ \\
\hline Exclusion by any criterion & $65.89(64.13-67.60)$ & $58.60(56.57-60.61)$ \\
\hline
\end{tabular}

$5{ }^{\mathrm{a}}$ Derived from the review of 54 randomized controlled clinical trials (method described in the

6 paper). 
2 Percentages are weighted values

3 NA: Information not available in the NESARC

4 


\section{References}

2

3 [1] Fiore MC, Jaén CR, Baker TB. Treating Tobacco Use and Dependence: 2008

$4 \quad$ Update. US Dept of Health and Human Services 2008.

5 [2] Le Foll B, George TP. Treatment of tobacco dependence: integrating recent progress

6 into practice. CMAJ 2007;177(11):1373-1380.

7 [3] Le Foll B, Melihan-Cheinin P, Rostoker G, et al. Smoking cessation guidelines:

8 evidence-based recommendations of the French Health Products Safety Agency. Eur

9 Psychiatry 2005;20(5-6):431-441.

10 [4] National Institute for Clinical Excellence. Brief interventions and referral for 11 smoking cessation in primary care and other settings. Public Health Intervention Guidance 12 No. 1, London: NICE 2006.

13 [5] Weisberg HI, Hayden VC, Pontes VP. Selection criteria and generalizability within

14 the counterfactual framework: explaining the paradox of antidepressant-induced suicidality?

15 Clin Trials 2009;6(2):109-118.

16 [6] Dzewaltowski DA, Estabrooks PA, Klesges LM, et al. Behavior change intervention

17 research in community settings: how generalizable are the results? Health Promot Int $18 \quad 2004 ; \mathbf{1 9}(2): 235-245$.

19 [7] Kamholz BW, Gulliver SB, Helstrom A, et al. Implications of participant self20 selection for generalizability: who participates in smoking laboratory research? Subst Use $21 \quad$ Misuse 2009;44(3):343-356.

22 [8] Weiss NS, Koepsell TD, Psaty BM. Generalizability of the results of randomized 23 trials. Arch Intern Med 2008;168(2):133-135. 
1 [9] Dhruva SS, Redberg RF. Variations between clinical trial participants and Medicare

2 beneficiaries in evidence used for Medicare national coverage decisions. Arch Intern Med $3 \quad 2008 ; \mathbf{1 6 8}(2): 136-140$.

4 [10] Blanco C, Olfson M, Goodwin R, et al. Generalizability of clinical trial results for 5 major depression to community samples: results from the National Epidemiologic Survey on 6 Alcohol and Related Conditions. J Clin Psychiatry 2008;69(8):1276-1280.

7 [11] Zimmerman M, Chelminski I, Posternak MA. Generalizability of antidepressant 8 efficacy trials: differences between depressed psychiatric outpatients who would or would not 9 qualify for an efficacy trial. Am J Psychiatry 2005;162(7):1370-1372.

10 [12] Zimmerman M, Mattia JI, Posternak MA. Are subjects in pharmacological treatment 11 trials of depression representative of patients in routine clinical practice? Am J Psychiatry $12 \quad 2002 ; 159(3): 469-473$.

13 [13] Posternak MA, Zimmerman M, Keitner GI, et al. A reevaluation of the exclusion 14 criteria used in antidepressant efficacy trials. Am J Psychiatry 2002;159(2):191-200.

15 [14] Zetin M, Hoepner CT. Relevance of exclusion criteria in antidepressant clinical 16 trials: a replication study. J Clin Psychopharmacol 2007;27(3):295-301.

17 [15] Boter H, Derks EM, Fleischhacker WW, et al. Generalizability of the results of 18 efficacy trials in first-episode schizophrenia: comparisons between subgroups of participants 19 of the European First Episode Schizophrenia Trial (EUFEST). J Clin Psychiatry 2009.

20 [16] Leucht S, Heres S, Hamann J, et al. Methodological issues in current antipsychotic 21 drug trials. Schizophr Bull 2008;34(2):275-285.

22 [17] Khan AY, Preskorn SH, Baker B. Effect of study criteria on recruitment and 23 generalizability of the results. J Clin Psychopharmacol 2005;25(3):271-275.

24 [18] Blanco C, Olfson M, Okuda M, et al. Generalizability of clinical trials for alcohol 25 dependence to community samples. Drug Alcohol Depend 2008;98(1-2):123-128. 
1 [19] Humphreys K, Weingardt KR, Harris AH. Influence of subject eligibility criteria on

2 compliance with National Institutes of Health guidelines for inclusion of women, minorities,

3 and children in treatment research. Alcohol Clin Exp Res 2007;31(6):988-995.

4 [20] Humphreys K, Weingardt KR, Horst D, et al. Prevalence and predictors of research

5 participant eligibility criteria in alcohol treatment outcome studies, 1970-98. Addiction

$6 \quad 2005 ; \mathbf{1 0 0}(9): 1249-1257$.

7 [21] Humphreys K, Weisner C. Use of exclusion criteria in selecting research subjects

8 and its effect on the generalizability of alcohol treatment outcome studies. Am J Psychiatry

$9 \quad 2000 ; \mathbf{1 5 7}(4): 588-594$.

10 [22] Okuda M, Hasin DS, Olfson M, et al. Generalizability of clinical trials for cannabis 11 dependence to community samples. Drug Alcohol Depend in press.

12 [23] Andrews JA, Severson HH, Akers L, et al. Who enrolls in a self-help cessation 13 program for smokeless tobacco? Addict Behav 2001;26(5):757-764.

14 [24] Graham AL, Bock BC, Cobb NK, et al. Characteristics of smokers reached and 15 recruited to an internet smoking cessation trial: a case of denominators. Nicotine Tob Res $16 \quad 2006 ; 8$ Suppl 1:S43-48.

17 [25] Howard-Pitney B, Fortmann SP, Killen JD. Generalizability of findings from a 18 chewing tobacco cessation clinical trial. Nicotine Tob Res 2001;3(4):347-352.

19 [26] Hughes JR. Data to estimate the similarity of tobacco research samples to intended 20 populations. Nicotine Tob Res 2004;6(1):177-179.

21 [27] Hughes JR, Callas PW. Data to assess the generalizability of samples from studies of 22 adult smokers. Nicotine Tob Res 2009.

23 [28] Robinson ML, Schroeder JR, Moolchan ET. Adolescent smokers screened for a 24 nicotine replacement treatment trial: correlates of eligibility and enrollment. Nicotine Tob Res $25 \quad 2006 ; 8(3): 447-454$. 
1 [29] Schmelzle J, Rosser WW, Birtwhistle R. Update on pharmacologic and

2 nonpharmacologic therapies for smoking cessation. Can Fam Physician 2008;54(7):994-999.

3 [30] Fagerstrom KO. Measuring degree of physical dependence to tobacco smoking with

4 reference to individualization of treatment. Addict Behav 1978;3(3-4):235-241.

5 [31] Grant BF, Dawson DA, Stinson FS, et al. The Alcohol Use Disorder and Associated

6 Disabilities Interview Schedule-IV (AUDADIS-IV): reliability of alcohol consumption,

7 tobacco use, family history of depression and psychiatric diagnostic modules in a general

8 population sample. Drug Alcohol Depend 2003;71(1):7-16.

9 [32] Grant BF, Dawson DA, Stinson FS, et al. The 12-month prevalence and trends in 10 DSM-IV alcohol abuse and dependence: United States, 1991-1992 and 2001-2002. Drug 11 Alcohol Depend 2004;74(3):223-234.

12 [33] Gorwood P. Clinical assessment in psychiatric genetics. In: Leboyer M, Bellivier F, 13 eds. Psychiatric Genetics: Methods and Protocols: John M. Walker, Humana Press Inc $14 \quad 2003: 99-126$.

15 [34] Grant B, Hasin D, Chou S, et al. Nicotine dependence and psychiatric disorders in 16 the United States: results from the national epidemiologic survey on alcohol and related 17 conditions. Arch Gen Psychiatry 2004;61(11):1107-1115.

18 [35] Grant BF, Harford TC, Dawson DA, et al. The Alcohol Use Disorder and 19 Associated Disabilities Interview schedule (AUDADIS): reliability of alcohol and drug 20 modules in a general population sample. Drug Alcohol Depend 1995;39(1):37-44.

21 [36] Eisenberg MJ, Filion KB, Yavin D, et al. Pharmacotherapies for smoking cessation: 22 a meta-analysis of randomized controlled trials. CMAJ 2008;179(2):135-144.

23 [37] Tsai ST, Cho HJ, Cheng HS, et al. A randomized, placebo-controlled trial of 24 varenicline, a selective alpha4beta2 nicotinic acetylcholine receptor partial agonist, as a new 25 therapy for smoking cessation in Asian smokers. Clin Ther 2007;29(6):1027-1039. 
1 [38] Nakamura M, Oshima A, Fujimoto Y, et al. Efficacy and tolerability of varenicline,

2 an alpha4beta2 nicotinic acetylcholine receptor partial agonist, in a 12-week, randomized,

3 placebo-controlled, dose-response study with 40-week follow-up for smoking cessation in

4 Japanese smokers. Clin Ther 2007;29(6):1040-1056.

5 [39] Fossati R, Apolone G, Negri E, et al. A double-blind, placebo-controlled,

6 randomized trial of bupropion for smoking cessation in primary care. Arch Intern Med $7 \quad 2007 ; 167(16): 1791-1797$.

8 [40] Oncken C, Gonzales D, Nides M, et al. Efficacy and safety of the novel selective 9 nicotinic acetylcholine receptor partial agonist, varenicline, for smoking cessation. Arch Intern Med 2006;166(15):1571-1577.

11 [41] Nides M, Oncken C, Gonzales D, et al. Smoking cessation with varenicline, a 12 selective alpha4beta2 nicotinic receptor partial agonist: results from a 7-week, randomized, 13 placebo- and bupropion-controlled trial with 1-year follow-up. Arch Intern Med $14 \quad 2006 ; 166(15): 1561-1568$.

15 [42] Jorenby DE, Hays JT, Rigotti NA, et al. Efficacy of varenicline, an alpha4beta2 16 nicotinic acetylcholine receptor partial agonist, vs placebo or sustained-release bupropion for 17 smoking cessation: a randomized controlled trial. JAMA 2006;296(1):56-63.

18 [43] Gonzales D, Rennard SI, Nides M, et al. Varenicline, an alpha4beta2 nicotinic 19 acetylcholine receptor partial agonist, vs sustained-release bupropion and placebo for smoking 20 cessation: a randomized controlled trial. JAMA 2006;296(1):47-55.

21 [44] Holt S, Timu-Parata C, Ryder-Lewis S, et al. Efficacy of bupropion in the 22 indigenous Maori population in New Zealand. Thorax 2005;60(2):120-123.

23 [45] Cooper TV, Klesges RC, Debon MW, et al. A placebo controlled randomized trial 24 of the effects of phenylpropanolamine and nicotine gum on cessation rates and postcessation 25 weight gain in women. Addict Behav 2005;30(1):61-75. 
1 [46] Dalsgareth OJ, Hansen NC, Soes-Petersen U, et al. A multicenter, randomized,

2 double-blind, placebo-controlled, 6-month trial of bupropion hydrochloride sustained-release

3 tablets as an aid to smoking cessation in hospital employees. Nicotine Tob Res 2004;6(1):55-

461.

5 [47] Collins BN, Wileyto EP, Patterson F, et al. Gender differences in smoking cessation

6 in a placebo-controlled trial of bupropion with behavioral counseling. Nicotine Tob Res

$7 \quad 2004 ; 6(1): 27-37$.

8 [48] Aubin HJ, Lebargy F, Berlin I, et al. Efficacy of bupropion and predictors of

9 successful outcome in a sample of French smokers: a randomized placebo-controlled trial.

10 Addiction 2004;99(9):1206-1218.

11 [49] Tonnesen P, Tonstad S, Hjalmarson A, et al. A multicentre, randomized, double-

12 blind, placebo-controlled, 1-year study of bupropion SR for smoking cessation. J Intern Med $13 \quad 2003 ; 254(2): 184-192$.

14 [50] Glavas D, Rumboldt M, Rumboldt Z. Smoking cessation with nicotine replacement 15 therapy among health care workers: randomized double-blind study. Croat Med J $16 \quad 2003 ; \mathbf{4 4}(2): 219-224$.

17 [51] Shiffman S, Dresler CM, Hajek P, et al. Efficacy of a nicotine lozenge for smoking 18 cessation. Arch Intern Med 2002;162(11):1267-1276.

19 [52] Hall SM, Humfleet GL, Reus VI, et al. Psychological intervention and 20 antidepressant treatment in smoking cessation. Arch Gen Psychiatry 2002;59(10):930-936.

21 [53] Glover ED, Glover PN, Franzon M, et al. A comparison of a nicotine sublingual 22 tablet and placebo for smoking cessation. Nicotine Tob Res 2002;4(4):441-450.

23 [54] Ahluwalia JS, Harris KJ, Catley D, et al. Sustained-release bupropion for smoking 24 cessation in African Americans: a randomized controlled trial. JAMA 2002;288(4):468-474. 
1 [55] Gonzales DH, Nides MA, Ferry LH, et al. Bupropion SR as an aid to smoking

2 cessation in smokers treated previously with bupropion: a randomized placebo-controlled

3 study. Clin Pharmacol Ther 2001;69(6):438-444.

4 [56] Wallstrom M, Nilsson F, Hirsch JM. A randomized, double-blind, placebo-

5 controlled clinical evaluation of a nicotine sublingual tablet in smoking cessation. Addiction

$6 \quad 2000 ; 95(8): 1161-1171$.

7 [57] Garvey AJ, Kinnunen T, Nordstrom BL, et al. Effects of nicotine gum dose by level 8 of nicotine dependence. Nicotine Tob Res 2000;2(1):53-63.

9 [58] Tonnesen P, Paoletti P, Gustavsson G, et al. Higher dosage nicotine patches increase 10 one-year smoking cessation rates: results from the European CEASE trial. Collaborative 11 European Anti-Smoking Evaluation. European Respiratory Society. Eur Respir J $12 \quad$ 1999;13(2):238-246.

13 [59] Jorenby DE, Leischow SJ, Nides MA, et al. A controlled trial of sustained-release 14 bupropion, a nicotine patch, or both for smoking cessation. N Engl J Med 1999;340(9):68515691.

16 [60] Hughes JR, Lesmes GR, Hatsukami DK, et al. Are higher doses of nicotine 17 replacement more effective for smoking cessation? Nicotine Tob Res 1999;1(2):169-174.

18 [61] Hays JT, Croghan IT, Schroeder DR, et al. Over-the-counter nicotine patch therapy 19 for smoking cessation: results from randomized, double-blind, placebo-controlled, and open 20 label trials. Am J Public Health 1999;89(11):1701-1707.

21 [62] Daughton D, Susman J, Sitorius M, et al. Transdermal nicotine therapy and primary 22 care. Importance of counseling, demographic, and participant selection factors on 1-year quit 23 rates. The Nebraska Primary Practice Smoking Cessation Trial Group. Arch Fam Med $24 \quad$ 1998;7(5):425-430. 
1 [63] Hurt RD, Sachs DP, Glover ED, et al. A comparison of sustained-release bupropion

2 and placebo for smoking cessation. N Engl J Med 1997;337(17):1195-1202.

3 [64] Hjalmarson A, Nilsson F, Sjostrom L, et al. The nicotine inhaler in smoking 4 cessation. Arch Intern Med 1997;157(15):1721-1728.

5 [65] Blondal T, Franzon M, Westin A. A double-blind randomized trial of nicotine nasal 6 spray as an aid in smoking cessation. Eur Respir J 1997;10(7):1585-1590.

7 [66] Schneider NG, Olmstead R, Nilsson F, et al. Efficacy of a nicotine inhaler in 8 smoking cessation: a double-blind, placebo-controlled trial. Addiction 1996;91(9):1293-1306.

9 [67] Paoletti P, Fornai E, Maggiorelli F, et al. Importance of baseline cotinine plasma 10 values in smoking cessation: results from a double-blind study with nicotine patch. Eur Respir $11 \quad J$ 1996;9(4):643-651.

12 [68] Hall SM, Munoz RF, Reus VI, et al. Mood management and nicotine gum in 13 smoking treatment: a therapeutic contact and placebo-controlled study. J Consult Clin Psychol 14 1996;64(5):1003-1009.

15 [69] Stapleton JA, Russell MA, Feyerabend C, et al. Dose effects and predictors of 16 outcome in a randomized trial of transdermal nicotine patches in general practice. Addiction $17 \quad$ 1995;90(1):31-42.

18 [70] Schneider NG, Olmstead R, Mody FV, et al. Efficacy of a nicotine nasal spray in 19 smoking cessation: a placebo-controlled, double-blind trial. Addiction 1995;90(12):1671201682.

21 [71] Kornitzer M, Boutsen M, Dramaix M, et al. Combined use of nicotine patch and 22 gum in smoking cessation: a placebo-controlled clinical trial. Prev Med 1995;24(1):41-47.

23 [72] Herrera N, Franco R, Herrera L, et al. Nicotine gum, 2 and $4 \mathrm{mg}$, for nicotine 24 dependence. A double-blind placebo-controlled trial within a behavior modification support 25 program. Chest 1995;108(2):447-451. 
1 [73] Gourlay SG, Forbes A, Marriner T, et al. Double blind trial of repeated treatment

2 with transdermal nicotine for relapsed smokers. BMJ 1995;311(7001):363-366.

3 [74] Hurt RD, Dale LC, Fredrickson PA, et al. Nicotine patch therapy for smoking

4 cessation combined with physician advice and nurse follow-up. One-year outcome and

5 percentage of nicotine replacement. JAMA 1994;271(8):595-600.

6 [75] Hjalmarson A, Franzon M, Westin A, et al. Effect of nicotine nasal spray on

7 smoking cessation. A randomized, placebo-controlled, double-blind study. Arch Intern Med

$8 \quad$ 1994;154(22):2567-2572.

9 [76] Fiore MC, Kenford SL, Jorenby DE, et al. Two studies of the clinical effectiveness

10 of the nicotine patch with different counseling treatments. Chest 1994;105(2):524-533.

11 [77] Westman EC, Levin ED, Rose JE. The nicotine patch in smoking cessation. A

12 randomized trial with telephone counseling. Arch Intern Med 1993;153(16):1917-1923.

13 [78] Tonnesen P, Norregaard J, Mikkelsen K, et al. A double-blind trial of a nicotine 14 inhaler for smoking cessation. JAMA 1993;269(10):1268-1271.

15 [79] Sachs DP, Sawe U, Leischow SJ. Effectiveness of a 16-hour transdermal nicotine 16 patch in a medical practice setting, without intensive group counseling. Arch Intern Med $17 \quad$ 1993;153(16):1881-1890.

18 [80] Effectiveness of a nicotine patch in helping people stop smoking: results of a 19 randomised trial in general practice. Imperial Cancer Research Fund General Practice 20 Research Group. BMJ 1993;306(6888):1304-1308.

21 [81] Sutherland G, Stapleton JA, Russell MA, et al. Randomised controlled trial of nasal 22 nicotine spray in smoking cessation. Lancet 1992;340(8815):324-329.

23 [82] Tonnesen P, Norregaard J, Simonsen K, et al. A double-blind trial of a 16-hour 24 transdermal nicotine patch in smoking cessation. N Engl J Med 1991;325(5):311-315. 
1 [83] Daughton DM, Heatley SA, Prendergast JJ, et al. Effect of transdermal nicotine

2 delivery as an adjunct to low-intervention smoking cessation therapy. A randomized, placebo-

3 controlled, double-blind study. Arch Intern Med 1991;151(4):749-752.

4 [84] Killen JD, Fortmann SP, Newman B, et al. Evaluation of a treatment approach

5 combining nicotine gum with self-guided behavioral treatments for smoking relapse

6 prevention. J Consult Clin Psychol 1990;58(1):85-92.

7 [85] Hall SM, Tunstall CD, Ginsberg D, et al. Nicotine gum and behavioral treatment: a 8 placebo controlled trial. J Consult Clin Psychol 1987;55(4):603-605.

9 [86] Hjalmarson AI. Effect of nicotine chewing gum in smoking cessation. A 10 randomized, placebo-controlled, double-blind study. JAMA 1984;252(20):2835-2838.

11 [87] Hughes JR, Gust SW, Keenan RM, et al. Nicotine vs placebo gum in general 12 medical practice. JAMA 1989;261(9):1300-1305.

13 [88] Jamrozik K, Fowler G, Vessey M, et al. Placebo controlled trial of nicotine chewing 14 gum in general practice. Br Med J(Clin Res Ed) 1984;289(6448):794-797.

15 [89] Jarvik ME, Schneider NG. Degree of addiction and effectiveness of nicotine gum 16 therapy for smoking. Am J Psychiatry 1984;141(6):790-791.

17 [90] Jarvis MJ, Raw M, Russell MA, et al. Randomised controlled trial of nicotine 18 chewing-gum. Br Med J (Clin Res Ed) 1982;285(6341):537-540.

19 [91] Malcolm RE, Sillett RW, Turner JA, et al. The use of nicotine chewing gum as an 20 aid to stopping smoking. Psychopharmacology (Berl) 1980;70(3):295-296.

21 [92] Schneider NG, Jarvik ME, Forsythe AB, et al. Nicotine gum in smoking cessation: a 22 placebo-controlled, double-blind trial. Addict Behav 1983;8(3):253-261.

23 [93] Leeman RF, Huffman CJ, O'Malley SS. Alcohol history and smoking cessation in 24 nicotine replacement therapy, bupropion sustained release and varenicline trials: a review. 25 Alcohol Alcohol 2007;42(3):196-206. 
1 [94] Lutsenko H, Doran CM, Hall WD. Australian smokers' use of bupropion and

2 nicotine replacement therapies and their relation to reimbursement, Australia 2001-05. Drug

3 Alcohol Rev 2008;27(2):160-164.

4 [95] Hudson JI, Hiripi E, Pope HG, Jr., et al. The prevalence and correlates of eating

5 disorders in the National Comorbidity Survey Replication. Biol Psychiatry 2007;61(3):3486358.

7 [96] Hurt RD, Offord KP, Croghan IT, et al. Mortality following inpatient addictions

8 treatment. Role of tobacco use in a community-based cohort. JAMA 1996;275(14):1097-1103.

9 [97] Le Strat Y, Ramoz N, Gorwood P. In alcohol-dependent drinkers, what does the 10 presence of nicotine dependence tell us about psychiatric and addictive disorders 11 comorbidity? Alcohol Alcohol 2010;45(2):167-172.

12 [98] Abelin T, Buehler A, Muller P, et al. Controlled trial of transdermal nicotine patch 13 in tobacco withdrawal. Lancet 1989;1(8628):7-10.

14 [99] Fortmann SP, Killen JD, Telch MJ, et al. Minimal contact treatment for smoking 15 cessation. A placebo controlled trial of nicotine polacrilex and self-directed relapse 16 prevention: initial results of the Stanford Stop Smoking Project. JAMA 1988;260(11):1575$17 \quad 1580$. 